\title{
Effect of Ground Motion Orientation on Seismic Responses of an Asymmetric Stress Ribbon Pedestrian Bridge
}

\author{
Yi Zhang $\mathbb{D},{ }^{1}$ Wuchuan Pu $\mathbb{D},{ }^{2}$ Qishuo Zhang $\mathbb{D}^{2},{ }^{2}$ Kaiwen Liu $\mathbb{D}^{2},{ }^{2}$ and Hua Dong ${ }^{1}$ \\ ${ }^{1}$ China Construction Third Bureau First Engineering Co., LTD., Wuhan 430040, China \\ ${ }^{2}$ School of Civil Engineering and Architecture, Wuhan University of Technology, Wuhan 430070, China \\ Correspondence should be addressed to Wuchuan Pu; puwuchuan@whut.edu.cn
}

Received 26 September 2021; Revised 5 February 2022; Accepted 8 February 2022; Published 3 March 2022

Academic Editor: Nicola Buratti

Copyright (c) 2022 Yi Zhang et al. This is an open access article distributed under the Creative Commons Attribution License, which permits unrestricted use, distribution, and reproduction in any medium, provided the original work is properly cited.

The stress ribbon bridge uses ribbon in high tension to transfer loads and exhibits geometric nonlinearity under dynamic earthquake excitations. A typical double-span asymmetric stress ribbon pedestrian bridge was introduced as a prototype, and nonlinear time history analysis was performed to investigate the effect of ground motion orientation on the structural responses. Non-pulse-type and pulse-type ground motions were considered, and the influence of vertical ground motions was investigated. Numerical results showed that the stress ribbon bridge's vertical and transverse displacements were sensitive to the excitation of the vertical ground motion. No single orientation led to the most critical values in all response indexes, and the critical orientation was approximately independent of the vertical ground motion. The negative bending moment of the ribbons, the pier top displacement, and the pier base moment at the transverse direction were sensitive to the ground motion orientation. Checking the responses resulting from different directions is necessary for a comprehensive estimation of the seismic performance of the stress ribbon bridge.

\section{Introduction}

The stress ribbon bridge is one of the essential bridge prototypes applied for a long history. Typically, it consists of cables or ribbons and concrete deck slabs placed on them. The vertical dead load and live load are supported by the cables or ribbons in a high-tension state, and the deck slabs serve to transfer the live load to the ribbons. Compared with other types of bridges, the stress ribbon bridge has lightweight, and it has a catenary shape that looks natural and aesthetically attractive. Notably, the increasing use of highstrength materials can minimize the construction material and resources, making stress ribbon bridges sustainable and, thus, more and more attractive worldwide. Many stress ribbon footbridges have been constructed, including the classic Lignon-Loex Bridge in Switzerland, IGA North Bridge in Rostock, and the Slinky Spring to Fame near Oberhausen, Germany [1]. For the stress ribbon bridges, the deck can be formed by a monolithic band or assembled with precast segments. In recent years, high-strength steel materials have been well developed, and using high-strength steel plates as ribbons of the bridge becomes more and more popular. For example, Goldack et al. [1] reported two bridges using S690L1 steel plates as ribbons. S690QL1 is a highstrength steel material prescribed by European code for engineering structures, and the yielding strength is $690 \mathrm{MPa}$. The bridges adopted two ribbons with a section size of $600 \mathrm{~mm} \times 30 \mathrm{~mm}$ and $460 \mathrm{~mm} \times 30 \mathrm{~mm}$, respectively, to bear the loads. Very recently, a stress ribbon bridge was constructed in Shenzhen, China. This bridge also adopted a thick $(40 \mathrm{~mm})$ steel plate as ribbons, and the high-strength steel material of the Chinese brand of Q690D was used. The utilization of these high-strength materials is advantageous for reducing the volume of materials and the construction labor. Such a structural prototype is becoming more and more attractive for pedestrian bridges.

The stress ribbon bridges are mainly applied to pedestrian bridges but seldom to highway bridges due to the possible significant change of bridge grade and excessive displacements during the passage of heavy vehicles. So far, 
the research efforts have been focused on the comfortability resulting from human walking [2-6] and aerodynamic properties [7]. On the other hand, the safety of the bridges subjected to earthquake excitations should also be strictly guaranteed [8]. In high-risk seismic zones, the earthquake may become the most critical factor that determines the structural configurations. Usually, an urban pedestrian bridge adopts a distinctive design from the perspective of aesthetics. However, bridges with irregular arrangements are generally more vulnerable to seismic excitations, which has been evident by failures and damage of bridges observed in recent major earthquake events [9-14]. The previous observations highlight the significance of seismic performance estimation of the stress ribbon bridges with irregular shapes, which has been seldom investigated in the past.

In the seismic analysis for bridges, the directionality of earthquake action is usually chosen arbitrarily by the designers. In seismic zones, bridges must be able to resist seismic actions coming from any direction. Previous research has shown that ignoring the ground motion directionality may lead to underestimating the seismic fragility of bridges $[15,16]$. The effect of ground motion directionality should be investigated so that the most unfavorable direction and the most critical response can be figured out.

As the stress ribbon bridge system is becoming more and more popular worldwide, clarifying its seismic performance and the influencing factors has become an essential issue. The stress ribbon bridge has significant geometrical nonlinearity, which makes the theoretical solution of dynamic response difficult. In such circumstances, numerical analysis based on the finite element model is an effective way to solve the problem. Given these facts, this article aims to investigate the effect of the orientation of the horizontal bidirectional ground motions on the responses of a stress ribbon bridge. The impacts of the vertical ground motion and scaling of the ground motion are also investigated. The article is organized as follows. The details of a stress ribbon bridge constructed in Shenzhen, China, are introduced first, and the finite element model is established by using this bridge as a prototype. Two sets of ground motions recorded in near-fault zones, one with and one without prominent impulsive characteristics, are selected. An extensive time history analysis is performed. The tridimensional displacements and the corresponding forces of the ribbons and the pier are recorded and compared. The effect of ground motion orientation and impulsive characteristics are discussed, and a few conclusions are summarized.

\section{Analytical Model of the Stress Ribbon Bridge}

2.1. Structural Layout. Figure 1 shows the structural layout of the stress ribbon bridge under consideration. The bridge has two spans and a total length of $88.1 \mathrm{~m}$. The length and initial sag under self-weight are $63.8 \mathrm{~m}$ and $1.5 \mathrm{~m}$, respectively, for the long span, and $24.3 \mathrm{~m}$ and $0.3 \mathrm{~m}$ for the short span. The height difference between the two abutments is $5.6 \mathrm{~m}$. The bridge's weight is transferred through two steel ribbons, and each ribbon has width and thickness being $0.75 \mathrm{~m}$ and $0.04 \mathrm{~m}$, respectively. The precast concrete deck has a width of $2.7 \mathrm{~m}$, and each concrete deck slab is connected to the ribbon by four bolts. The steel ribbon is made of high-strength Q690D steel material, which has been seldom used in civil structures in China. The Q690D exhibits appreciable strength but poor deformability. A yield-totensile strength ratio of more than 0.9 and the elongation ratio lower than $20 \%$ were obtained from the experiments [17]. The deformability of Q690D is not as good as the steel materials popularly used in civil structures in China, such as Q235 [18]. However, the high strength is attractive for reducing the weight of structural systems, and it is increasingly used in civil structures, particularly those expected to be elastic under design earthquakes.

The pier is set to reduce the excessive sag of the ribbon. It is constructed obliquely with a certain angle, which can reduce the height of the pier and enhance the bridge's aesthetic. For stress ribbon bridges in a static state, the tension forces of the ribbons are mainly governed by the sag. Through adjusting the initial sag of the two spans, the tension forces of the ribbons can be designed. The inclined pier is applied by both the vertical load and the horizontal force. The horizontal force results from the difference in the tension force between the two spans. In the design, the tension force of the short span is more significant than that of the long span; thus, the pier bears a horizontal thrust toward the short span. The horizontal and vertical force acting on the pier generate bending moments with different signs, and thus the bending moment and the stress at the pier base are reduced [19]. The material of the pier is Q420 C with a yield strength of $420 \mathrm{MPa}$. A saddle is erected on the top of the pier to support the ribbon. The saddle is curved so that the additional bending stress of the ribbon stays within the allowable limit. The ribbons and saddle are connected through welding in the central part of the saddle. At both free ends of the saddle, the ribbon may contact or leave the saddle depending on the loading level. Such type of curved saddle has been used in many stress ribbon bridges [1].

According to the Chinese seismic design code for urban bridges [20], the irregular bridge can be identified if any of the specific indices, such as the span length, the pier height, the span length ratio, the stiffness ratio of piers, the foundation conditions, and the axial compression ratio, exceeds the corresponding threshold. For estimating the response of irregular bridges, time history analysis is generally required [12]. The stress ribbon bridge in consideration (Figure 1) is characterized by many geometrical irregular factors, such as the significant height difference of the two abutments, the unequal span length, and the inclined pier. Therefore, it may be hard for static performance estimation to reflect its seismic behavior under earthquake loadings.

2.2. Finite Element Model of the Stress Ribbon Bridge. The analytical model of the stress ribbon bridge was established through finite element program ANSYS. Except for the part on the saddle, the ribbons were simulated by beam elements, and the ribbon on the saddle is simulated 


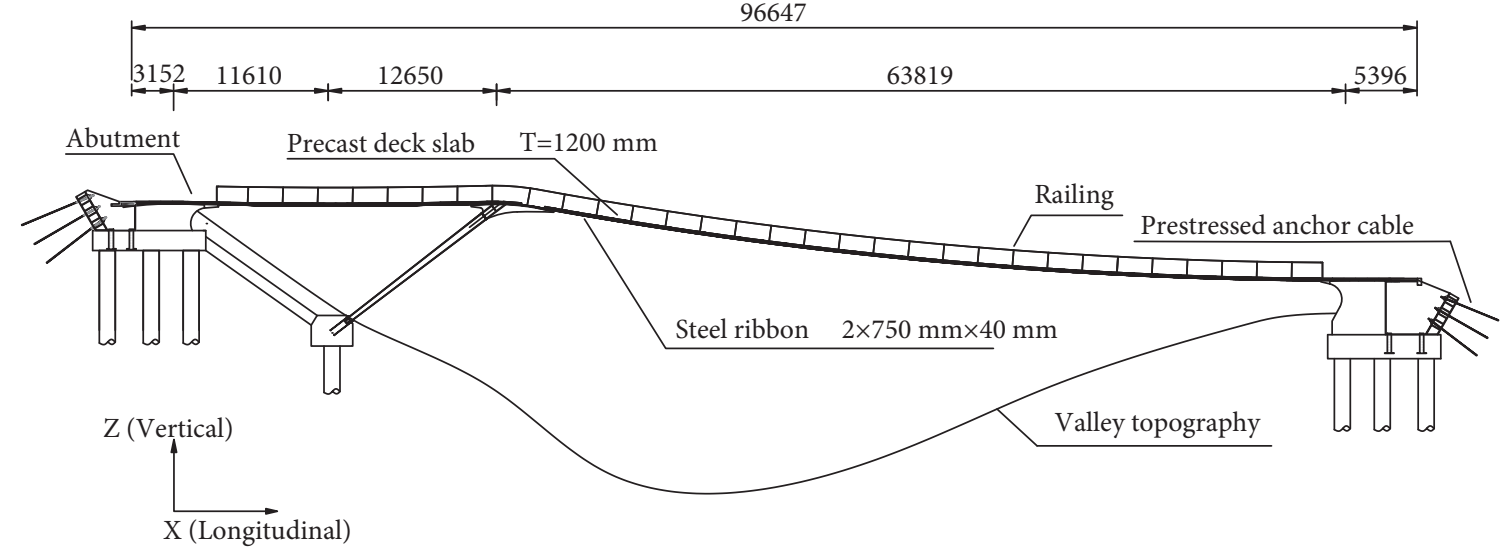

(a)

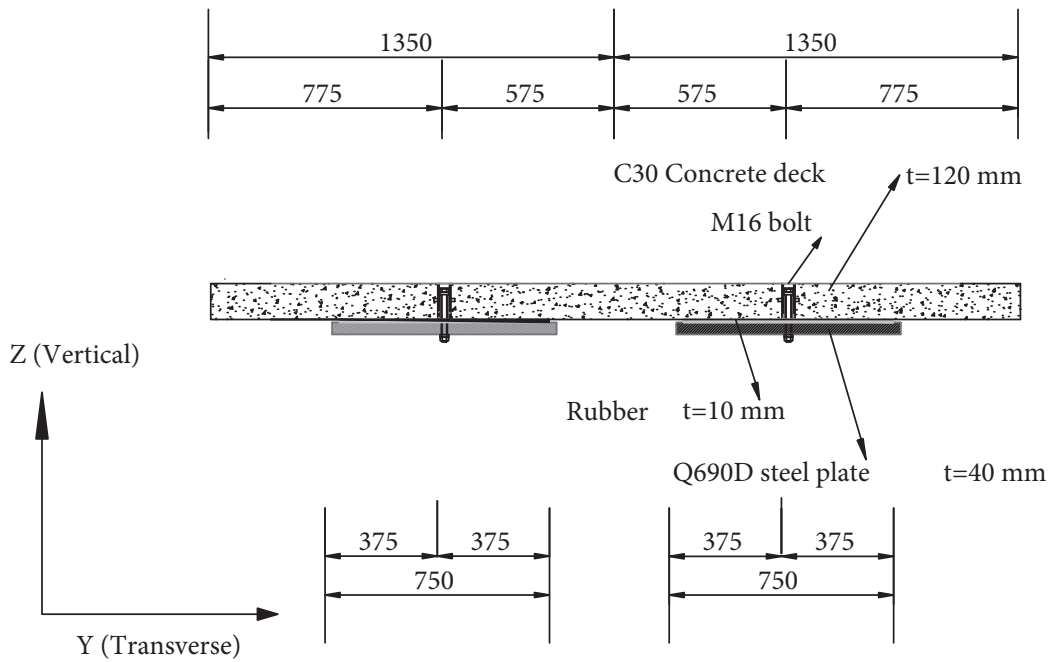

(b)

FIgURE 1: Sketch of the stress ribbon bridge. (a) Overall sketch of the bridge. (b) Transverse section.

by the plate element. The ribbon is characterized by the vertical stiffness varied with the tension force, which is called stress stiffening. Due to this effect, the bridge exhibits significant geometrical nonlinear behaviors $[23,24]$. For thin structures with bending stiffness very small compared to axial stiffness, including the stress ribbon bridges, stress stiffening needs to be considered. In the program, the effect of stress stiffening can be accounted for by generating and adding an additional stiffness matrix to the regular material stiffness matrix. The total stiffness $\mathbf{K}_{t}$ of the structure is the sum of the material stiffness $\mathbf{K}_{m}$ and stress stiffness matrix $\mathbf{K}_{s}(\sigma)$, namely, $\mathbf{K}_{t}=\mathbf{K}_{m}+\mathbf{K}_{s}(\sigma)$. The stress stiffness matrix can be derived in an updated Lagrangian formulation [25]. The stress stiffness matrix is represented as a function of the stress state of the structural element; thus, the stress stiffness matrix is generally computed based on the stress state of the previous equilibrium iteration. For solving a valid stress-stiffened problem, at least two iterations are required, with the first iteration being used to determine the stress state that will be used to generate the stress stiffness matrix of the second iteration. If this additional stiffness affects the stresses, more iterations need to be done to obtain a converged solution.

Moreover, there is a contact effect between the saddle and the ribbons within the nonwielding regions. In the numerical model, the surface-to-surface contact pair was defined to simulate the contact between the two bodies. The curved saddle was set to be the "target surface" and simulated by TARGE170 element; the ribbon was set to be the "contact surface" and simulated by CONTA174 element. The friction between the two surfaces was accounted for and the friction coefficient was 0.6.

The eigenvalue analysis was performed to understand the dynamic properties of the bridge. Figure 2 shows the first ten modes of vibration and the corresponding vibrational frequencies. Except for No.5, the other nine modes occur within the long span, and most of the modes result from vertical vibration. The natural frequencies of vibrational modes are ranged between $0.89 \mathrm{~Hz}$ and $2.9 \mathrm{~Hz}$, indicating that the frequencies of the neighboring modes are very close. There is a high probability of modal superposition among the torsional mode and vertical modes, which is a critical factor affecting the seismic 


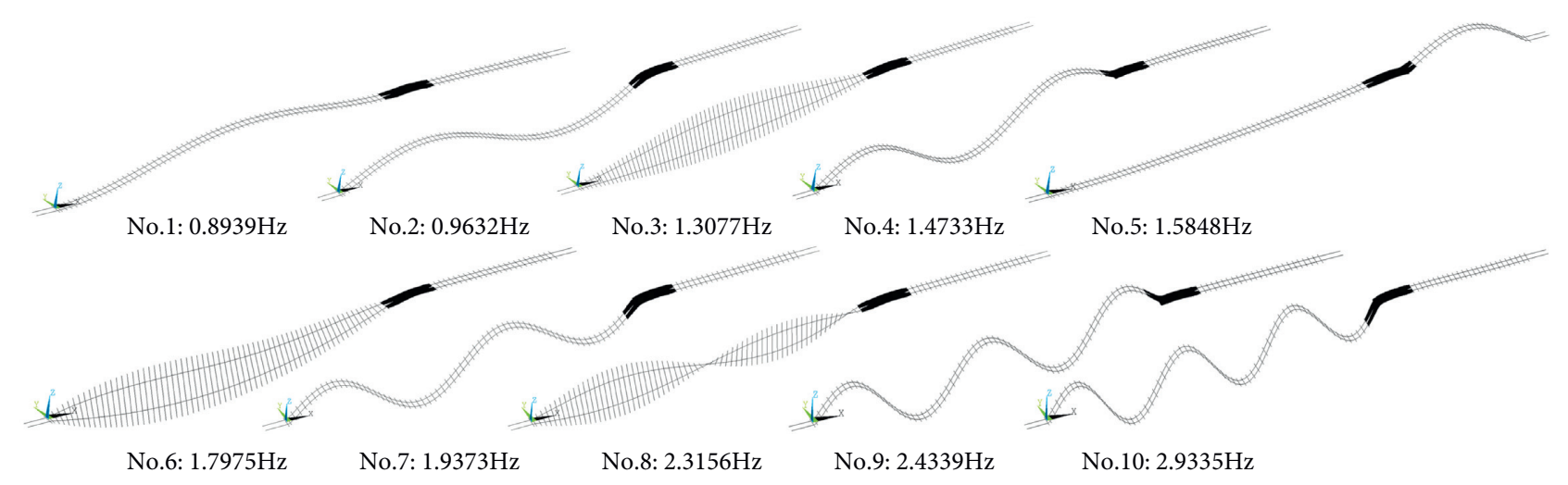

Figure 2: The first ten vibration modes of the stress ribbon bridge.

responses of the bridge. The Rayleigh damping model is used to simulate the inherent damping of the bridge, and the first and the second model are assumed to be $2 \%$.

\section{Selected Ground Motion Records}

Two sets of ground motions, including pulse-type and nonpulse-type records, were selected for performing time history analysis on the bridge. Each group consists of four ground motions. All the ground motions were selected from earthquake events with a magnitude between 6.5 and 7.5 and from stations with site-source distances less than $20 \mathrm{~km}$. All the ground motions were selected from near-fault stations because the vertical component is more prominent for structures close to the active fault [26]. Meanwhile, the vertical to horizontal component intensity ratios of all the selected ground motions are comparable, and it has been revealed by Shahi and Baker [27] that the site-source distance has a very minimal influence on the directionality. Table 1 gives the general information for the selected records, among which No.1-4 are non-pulse-type records, and No.5-8 are pulse-type records. The records were downloaded from the Pacific Earthquake Engineering Research (PEER) Center strong motion database [21]. In Table 1, RSN denotes the record sequence number that helps identify the record from the database; PGA, PGV, and PGD denote the peak ground acceleration, peak ground velocity, and peak ground displacement, respectively, at a specific direction. The significant duration computed as the time interval between the 5\% and 95\% Arias intensity is also shown. The pulse period is one of the most important parameters to characterize the pulse-type ground motions. For the pulsetype ground motions of No.5-No.8, their pulse periods are $0.931 \mathrm{sec}, 0.84 \mathrm{sec}, 1.092 \mathrm{sec}$, and $0.882 \mathrm{sec}$, respectively. The pulse periods are close to the fundamental vibration period of the bridge, which is usually considered a scenario for obtaining the critical structural responses.

In order to investigate the orientation effect, the horizontal ground motion pairs are rotated from $0^{\circ}$ to $90^{\circ}$ with an increment of $10^{\circ}$ by means of (1), where $a_{x}(t)$ and $a_{y}(t)$ are the originally recorded time series, and $a_{x}^{\prime}(t)$ and $a_{y}^{\prime}(t)$ are the time series rotated with an angle $\theta$.

$$
\left\{\begin{array}{l}
a_{x}^{\prime}(t) \\
a_{y}^{\prime}(t)
\end{array}\right\}=\left[\begin{array}{cc}
\cos \theta & -\sin \theta \\
\sin \theta & \cos \theta
\end{array}\right]\left\{\begin{array}{l}
a_{x}(t) \\
a_{y}(t)
\end{array}\right\} .
$$

The PGA, PGV, and PGD obtained from all directions (from $0^{\circ}$ to $180^{\circ}$ ) are shown in Figures 3 and 4, for non-pulsetype and pulse-type ground motions, respectively. The rotation angle of $0^{\circ}$ corresponds to the first horizontal component of each record, as given in Table 1 . The peak values vary significantly with the orientation; for example, for the RSN1051 record, the maximum PGV is approximately three times the minimum PGV. Moreover, the maximum PGA, PGV, and PGD of a record were obtained from different orientations. No single orientation develops the most critical values for all the intensity measures. The coefficient of variation (COV) of intensity measure over all directions is calculated, and the average COV of PGA, PGV, and PGD over the eight records is $0.16,0.21$, and 0.27 , respectively.

Figure 5 shows a 3 -dimensional graphic of the acceleration spectra of the horizontal component of the RSN953 record, with the rotation angle varying from $0^{\circ}$ to $180^{\circ}$. It is seen that the change of orientation leads to a corresponding variation in spectral shape. The difference between the spectra obtained from the neighboring two directions is generally slight; however, the spectral value may be considerably different at a specific period, for very different two orientations.

Usually, the effect of vertical ground motion is nonignorable for large-scale or irregular structures in high-risk seismic zones. Chinese seismic code regulated that the vertical ground motion should be considered for arch structures, long cantilever structures, and large-span structures against the seismic intensity level above eight. For this seismic level, the peak ground acceleration corresponding to the reoccurrence period of 475 years is $0.2 \mathrm{~g}$. In seismic design, the design spectrum of the vertical ground motion can be considered 0.65 times the design spectrum of horizontal components. From Table 1, it is known that, for non-pulse-type records, the ratios between the PGA of the vertical and horizontal component are $0.65,0.6,0.61$, and 0.76 , respectively; for pulse-type records, the proportions are $0.34,0.79,0.41$, and 0.25 , respectively. The intensity difference between the vertical and horizontal components is 
TABLE 1: General information of selected ground motions.

\begin{tabular}{|c|c|c|c|c|c|c|c|c|c|}
\hline No. & Event & RSN & $M_{\mathrm{w}}$ & $R(\mathrm{~km})$ & Component & PGA (g) & $\mathrm{PGV}(\mathrm{cm} / \mathrm{s})$ & PGD $(\mathrm{cm})$ & Duration (sec) \\
\hline \multirow{3}{*}{1} & \multirow{3}{*}{ Northridge-01 } & \multirow{3}{*}{953} & \multirow{3}{*}{6.69} & \multirow{3}{*}{9.44} & 9 & 0.44 & 59.2 & 15.5 & 9.3 \\
\hline & & & & & 279 & 0.49 & 66.6 & 12.2 & 8.1 \\
\hline & & & & & UD & 0.32 & 20.3 & 2.8 & 9.1 \\
\hline \multirow{3}{*}{2} & \multirow{3}{*}{ Northridge-01 } & \multirow{3}{*}{978} & \multirow{3}{*}{6.69} & \multirow{3}{*}{17.82} & 90 & 0.14 & 12.7 & 4.8 & 15.5 \\
\hline & & & & & 180 & 0.25 & 27.0 & 5.5 & 12.6 \\
\hline & & & & & UD & 0.15 & 11.7 & 4.0 & 18.1 \\
\hline \multirow{3}{*}{3} & \multirow{3}{*}{ Tottori, Japan } & \multirow{3}{*}{3934} & \multirow{3}{*}{6.61} & \multirow{3}{*}{16.6} & EW & 0.18 & 21.9 & 11.5 & 14.0 \\
\hline & & & & & NS & 0.15 & 21.7 & 10.5 & 15.6 \\
\hline & & & & & UD & 0.11 & 6.1 & 2.2 & 16.0 \\
\hline \multirow{3}{*}{4} & \multirow{3}{*}{ Darfield, New Zealand } & \multirow{3}{*}{6889} & \multirow{3}{*}{7} & \multirow{3}{*}{18.4} & 1 & 0.21 & 67.1 & 59.9 & 20.3 \\
\hline & & & & & 89 & 0.15 & 21.6 & 11.6 & 26.6 \\
\hline & & & & & UD & 0.16 & 16.0 & 12.5 & 19.6 \\
\hline \multirow{3}{*}{5} & \multirow{3}{*}{ Northridge-01 } & \multirow{3}{*}{1004} & \multirow{3}{*}{6.69} & \multirow{3}{*}{0} & 270 & 0.75 & 77.6 & 11.8 & 8.2 \\
\hline & & & & & 360 & 0.93 & 76.2 & 17.7 & 8.5 \\
\hline & & & & & UD & 0.32 & 25.0 & 11.1 & 10.5 \\
\hline \multirow{3}{*}{6} & \multirow{3}{*}{ Northridge-01 } & \multirow{3}{*}{1051} & \multirow{3}{*}{6.69} & \multirow{3}{*}{4.92} & 104 & 1.58 & 54.8 & 5.5 & 5.4 \\
\hline & & & & & 194 & 1.29 & 103.3 & 22.2 & 5.9 \\
\hline & & & & & UD & 1.23 & 49.1 & 11.3 & 5.7 \\
\hline \multirow{3}{*}{7} & \multirow{3}{*}{ Kobe, Japan } & & & & 0 & 0.83 & 91.0 & 21.1 & 8.4 \\
\hline & & 1106 & 6.9 & 0.94 & 90 & 0.63 & 76.0 & 18.3 & 9.5 \\
\hline & & & & & UD & 0.34 & 40.3 & 14.4 & 9.7 \\
\hline & & & & & 0 & 0.74 & 55.9 & 25.6 & 8.5 \\
\hline 8 & Duzce, Turkey & 1602 & 7.14 & 12.02 & 90 & 0.81 & 65.8 & 13.1 & 9.0 \\
\hline & & & & & UD & 0.20 & 23.4 & 13.9 & 12.5 \\
\hline
\end{tabular}

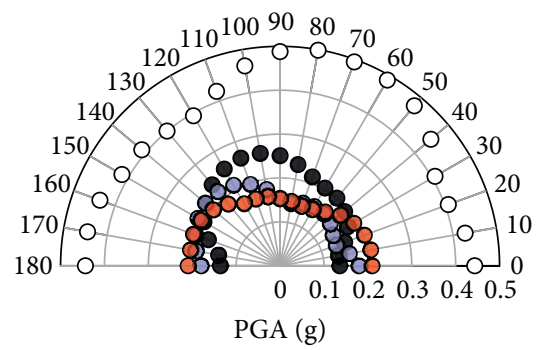

- RSN978

O RSN953

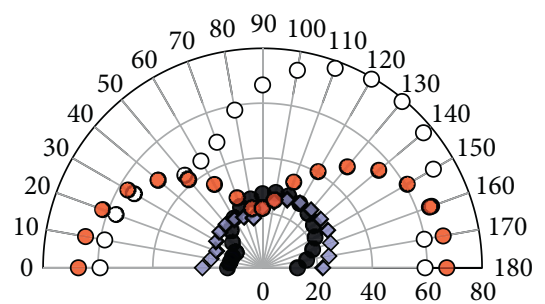

$\operatorname{PGV}(\mathrm{cm} / \mathrm{s})$

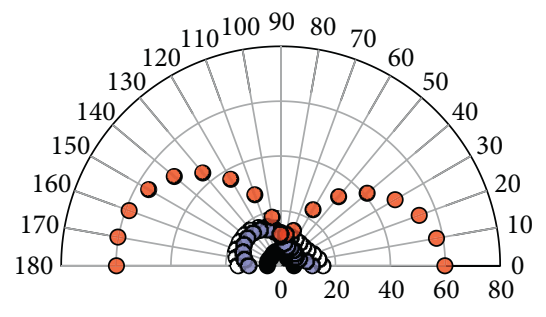

PGD $(\mathrm{cm})$

O RSN3934

O RSN6889

FIgURE 3: The peak values of non-pulse-type ground motions varied with orientation.

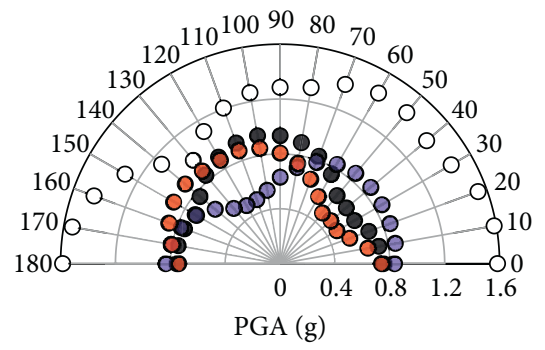

- RSN1004

O RSN1051

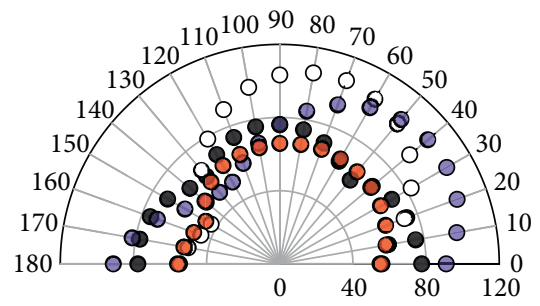

$\operatorname{PGV}(\mathrm{cm} / \mathrm{s})$

\section{O RSN1106}

O RSN1602

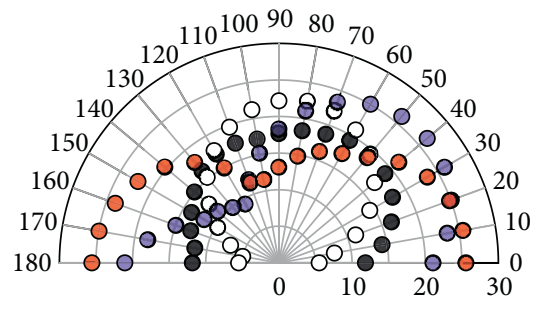

PGD $(\mathrm{cm})$

FIGURE 4: The peak values of pulse-type ground motions varied with orientation.

much more significant for pulse-type records. In the following, the effect of the vertical component on the structural response is investigated. When the horizontal components are rotated, the vertical component remains unchanged. The rotated tridirectional ground motions can be derived through . 


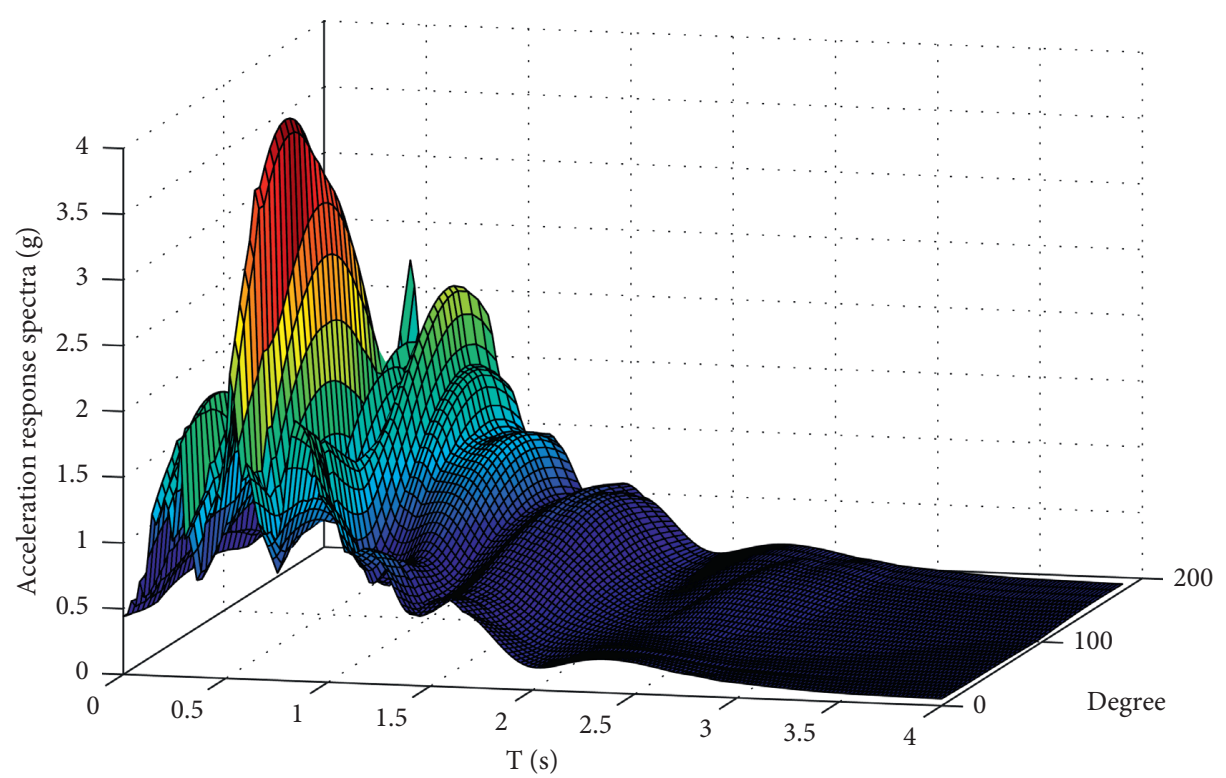

FIGURE 5: The acceleration response spectra of the horizontal components of the RSN953 record.

$$
\left\{\begin{array}{l}
a_{x}^{\prime}(t) \\
a_{y}^{\prime}(t) \\
a_{z}^{\prime}(t)
\end{array}\right\}=\left[\begin{array}{ccc}
\cos \theta & -\sin \theta & 0 \\
\sin \theta & \cos \theta & 0 \\
0 & 0 & 1
\end{array}\right]\left\{\begin{array}{l}
a_{x}(t) \\
a_{y}(t) \\
a_{z}(t)
\end{array}\right\}
$$

Figure 6 illustrates the acceleration response spectra for the strong horizontal component (with large PGA), the weak horizontal component (with small PGA), and the vertical component. In the following, the PGA of the strong horizontal component was scaled to match the target value, and the other two components were subsequently scaled with the same proportion.

\section{Seismic Response of the Stress Ribbon Bridge}

4.1. Effect of Ground Motion Intensity on the Response. The flexible ribbon exhibits geometric nonlinearity correlated with its tension force. During the dynamic vibration, the influence of geometric nonlinearity on the various response quantities is worthy of investigation. For clarifying this effect, the RSN 953 record was scaled to $0.1 \mathrm{~g}, 0.2 \mathrm{~g}, 0.3 \mathrm{~g}$, and $0.4 \mathrm{~g}$, and nonlinear time history analysis was performed. For the convenience of comparison, all the responses are normalized by the result obtained from $\mathrm{PGA}=0.1 \mathrm{~g}$. Figure 7 (a) shows the tension force and the bending moments of the ribbons and the pier; Figure $7(\mathrm{~b})$ shows the tridirectional displacements. The responses shown in Figures 7(a) and 7(b) include the response induced by the self-weight of the bridge. Figures $7(\mathrm{c})$ and $7(\mathrm{~d})$ show the responses excluding the contribution of self-weight. It is seen that as the PGA increases, all the forces and displacements increase as well, while the increase proportion is slightly reduced as PGA becomes large. The increments in different response quantities are different, and the increases in most of the response quantities are less than the increase proportion in the PGA. For example, when the PGA was increased from $0.1 \mathrm{~g}$ to $0.4 \mathrm{~g}$, the increases in the normalized responses of most of the response indexes are less than 4 . Notably, the increase in the longitudinal displacement and vertical displacement of the ribbon is limited. For the stress ribbon bridge, the axial force of the ribbon becomes large as the displacement increases, which further leads to the increase in the stiffness of the steel ribbon. Therefore, under elastic stage, it is expected that the displacement increase caused by an increased ground motion intensity will be limited due to the enhanced stiffness.

4.2. Directionality of Seismic Responses. The critical orientation is defined as the direction from which the maximum structural response is obtained among all the rotated versions of ground motion. For each earthquake record, ten sets of bidirectional horizontal components and ten sets of tridirectional components were generated, and time history analysis was performed based on each set of ground motion. The following responses were obtained from the nonlinear time history analysis: the tridimensional displacements (vertical, longitudinal, and transverse displacement), the tension force and the negative bending moment of the ribbons, the pier top tridimensional displacement, and the pier base bending moment.

Figure 8(a) shows the midspan displacements of the long span under bidirectional excitations of RSN953, and Figure 8(b) shows the counterpart results caused by the tridimensional excitations. The static vertical displacement of the midspan under self-weight was not included. It is observed that, even under bidirectional excitations, the vertical and transverse displacements are greater than the longitudinal ones. The transverse displacement is nonignorable for the stress ribbon bridge. The result is consistent with the mode shape (Figure 2), mainly resulting from the vertical displacement. When the vertical ground motion was input simultaneously (Figure 8(b)), the vertical displacement increased by $35 \%$, and the transverse displacement remained 


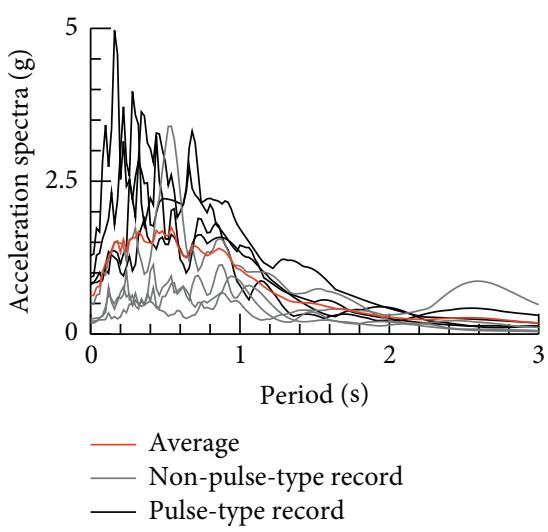

(a)

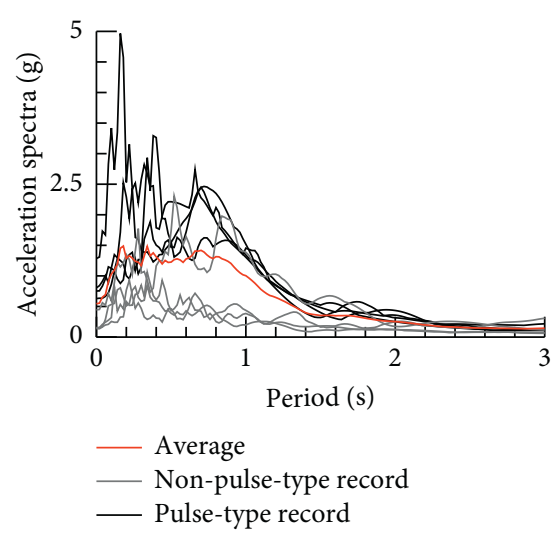

(b)

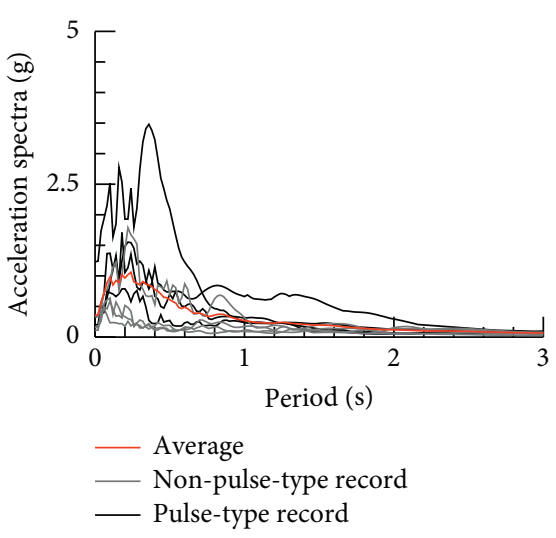

(c)

FIGURE 6: Response spectra of strong component, weak component, and vertical component of the selected records. (a) Strong component. (b) Weak component. (c) Vertical component.

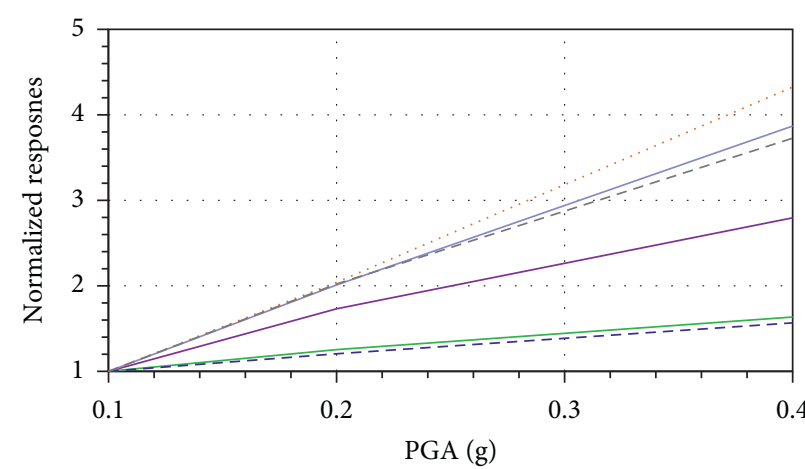

Tension force of long-span

- Longitudinal bending moment of long-span

_ Longitudinal bending moment of short-span

- - - Longitudinal bending moment at pier base

…. Torsional moment at pier base

- - - Transverse bending moment at pier base

(a)

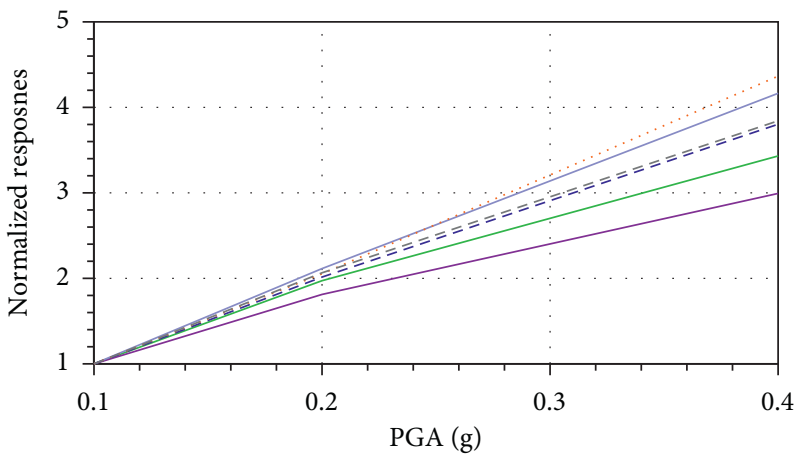

_ Tension force of long-span

— Longitudinal bending moment of long-span

- Longitudinal bending moment of short-span

- - - Longitudinal bending moment at pier base

…. Torsional moment at pier base

- - - Transverse bending moment at pier base

(c)

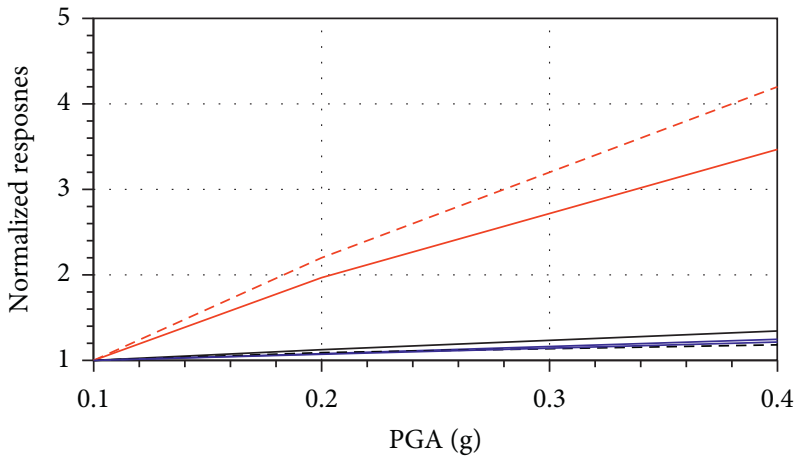

- Longitudinal displ. of long-span

_ Transverse displ. of long-span

— Vertical displ. of long-span

- - Longitudinal displ. of pier top

- - - Transverse displ. of pier top

— Vertical displ. of pier top

(b)

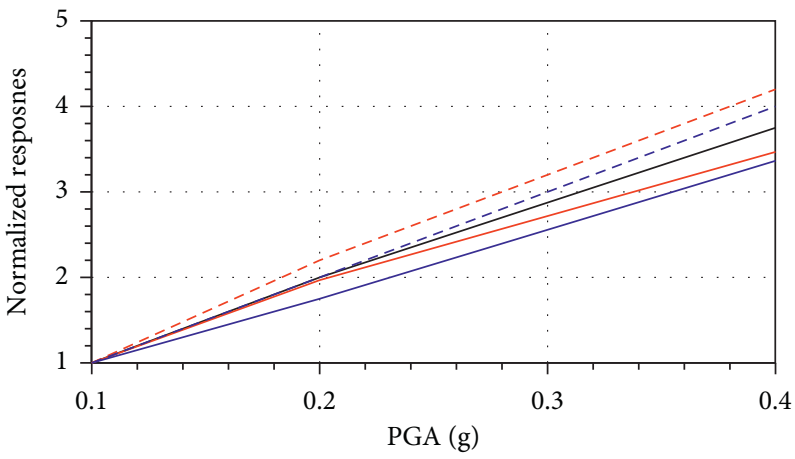

- Longitudinal displ. of long-span

_ Transverse displ. of long-span

— Vertical displ. of long-span

- - - Longitudinal displ. of pier top

- - - Transverse displ. of pier top

_ Vertical displ. of pier top

(d)

FIGURE 7: Responses varied with the intensity of ground motions. (a) The force responses considering self-weight. (b) The displacement response considering self-weight. (c) The force responses excluding self-weight. (d) The displacement response excluding self-weight. 


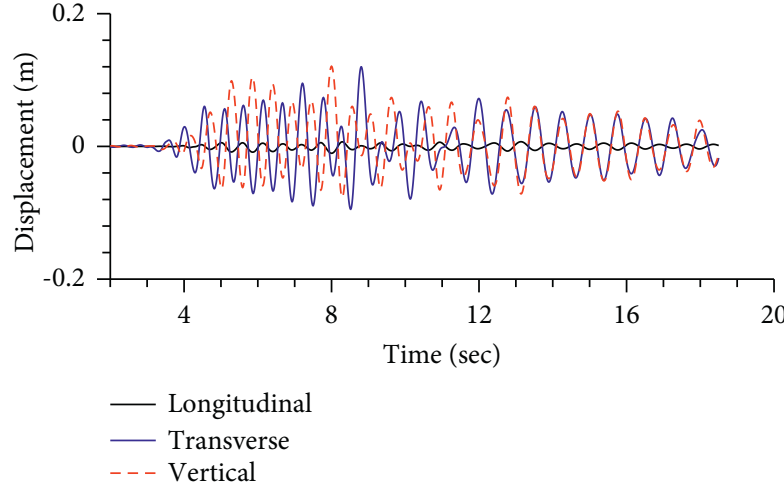

(a)

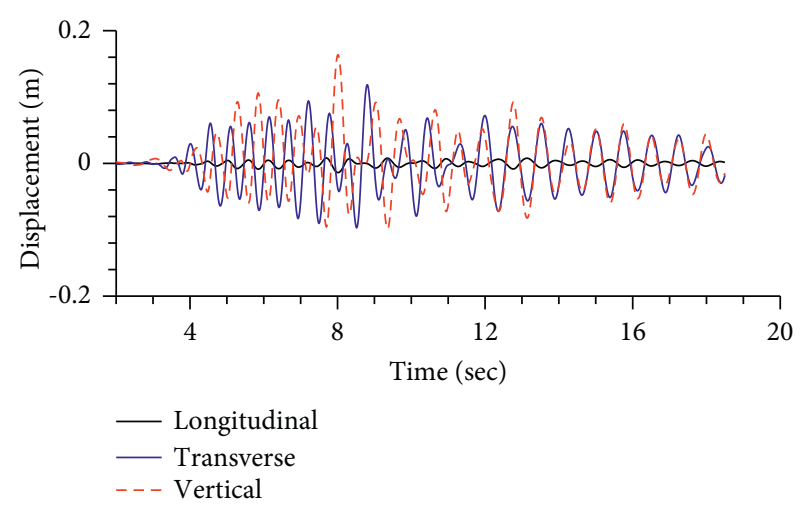

(b)

Figure 8: Time history of the midspan displacement of the long span. (a) Bidirectional excitation. (b) Tridirectional excitation.
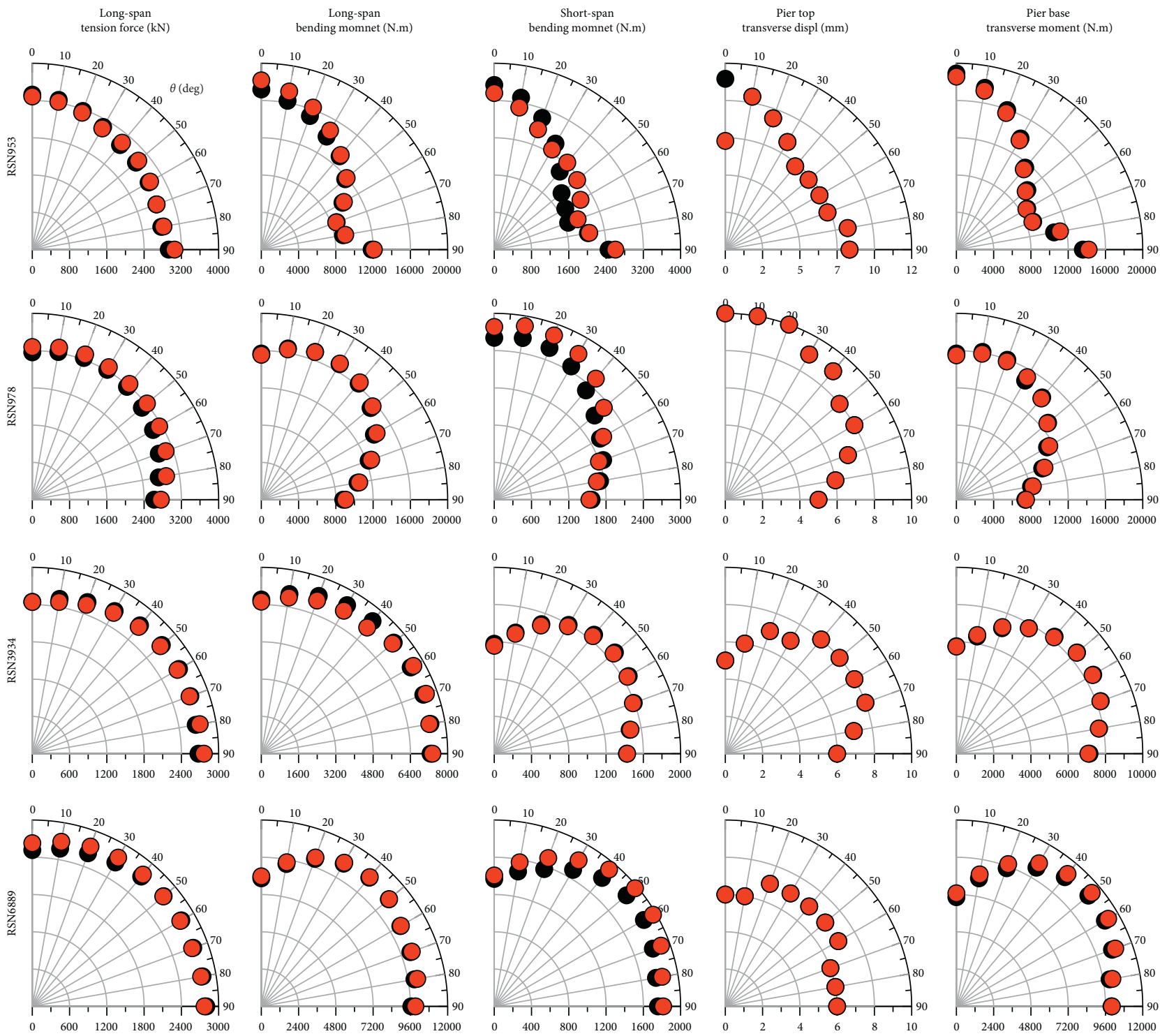

FiguRE 9: Distribution of responses obtained from non-pulse-type ground motions. 

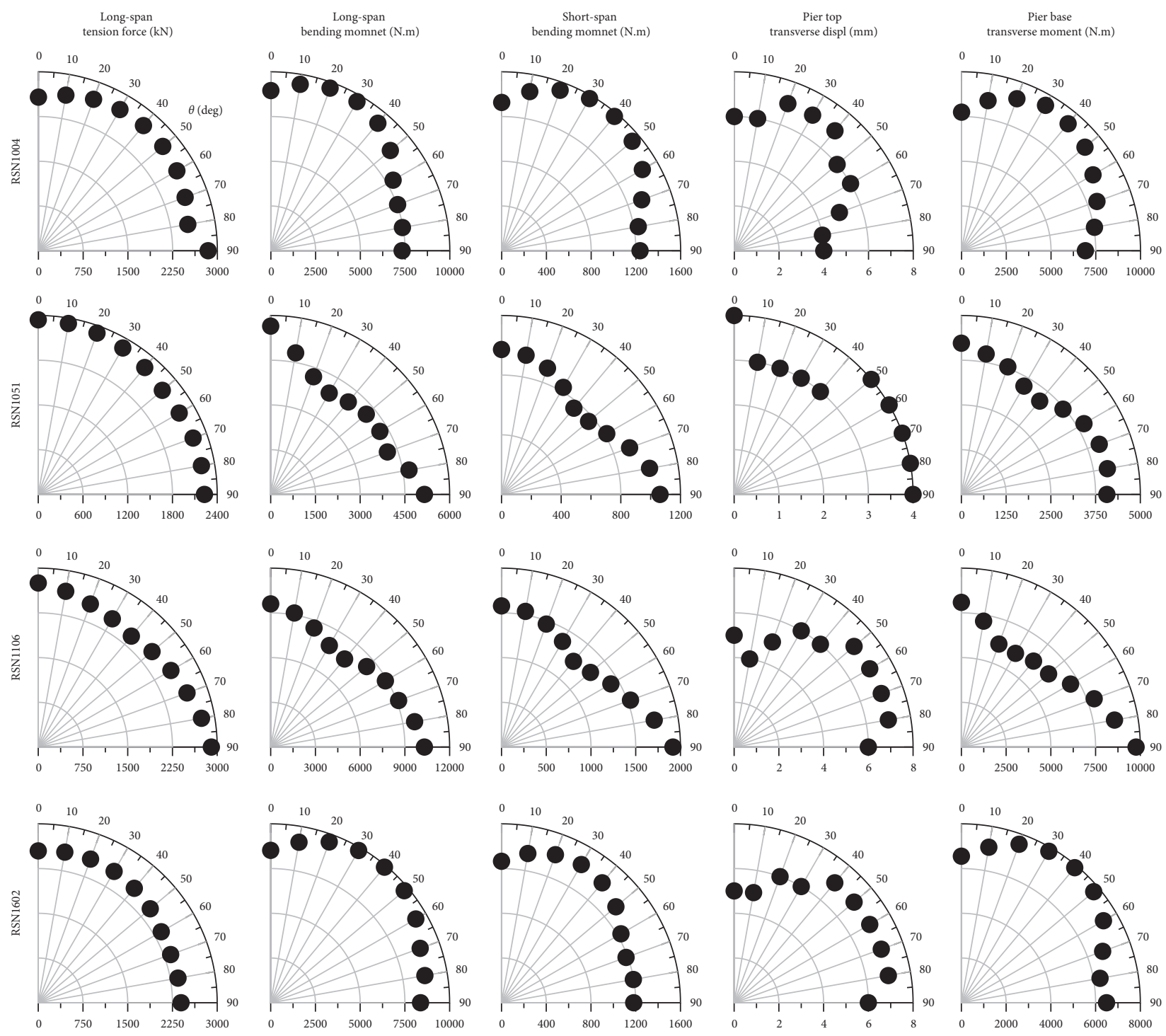

FIGURE 10: Distribution of responses obtained from pulse-type ground motions.

the same. The vertical excitation caused a significant increase in the longitudinal displacement from $0.01 \mathrm{~m}$ to $0.013 \mathrm{~m}$; however, the displacement was still a very small value.

Figure 9 shows the maximum responses obtained from the ten rotated versions of ground motions. The thrust of the ribbon, the negative bending moments of the ribbon at both spans, the transverse displacement of the pier top, and the transverse bending moment of the pier base were presented. These indexes are considered important because they determine the stress of the structural component. The rotation angle varied between $0^{\circ}$ and $90^{\circ}$. Similarly, take the RSN 953 record as an example. In case the tridirectional ground motions were input, the critical direction for thrust occurs at $0^{\circ}$, corresponding to the version that the weak horizontal component with PGA of $0.44 \mathrm{~g}$ was input to the longitudinal direction and the other component input to the transverse direction. From Figure 9, the influence of ground motion direction can be identified. Generally, the vertical ground motion has little influence on the selected responses of the bridges. The responses induced by tridimensional excitations may be slightly larger than those obtained from bidimensional excitations at a specific direction and for a specific type of response, as shown in Figure 8. However, adding the vertical excitation to the stress ribbon bridge is not expected to change the critical direction of the horizontal components. Therefore, in most cases, it will not induce much error in estimating the critical orientation for the selected responses if ignoring the vertical excitation.

The insignificant effect of the vertical component may lie in several aspects. First, the energy content of the vertical ground motion tends to be less than that in horizontal ground motion over a larger frequency domain. It can be observed from Figure 6 that the peak spectral values for vertical components located in a period range approximately from 0.1 s to $0.3 \mathrm{~s}$; in contrast, the counterparts for horizontal components located in the broader period range, mainly due to the contribution of the pulse-type ground motions. Second, the responses shown in Figure 9 may not be sensitive to the vertical ground motions. 

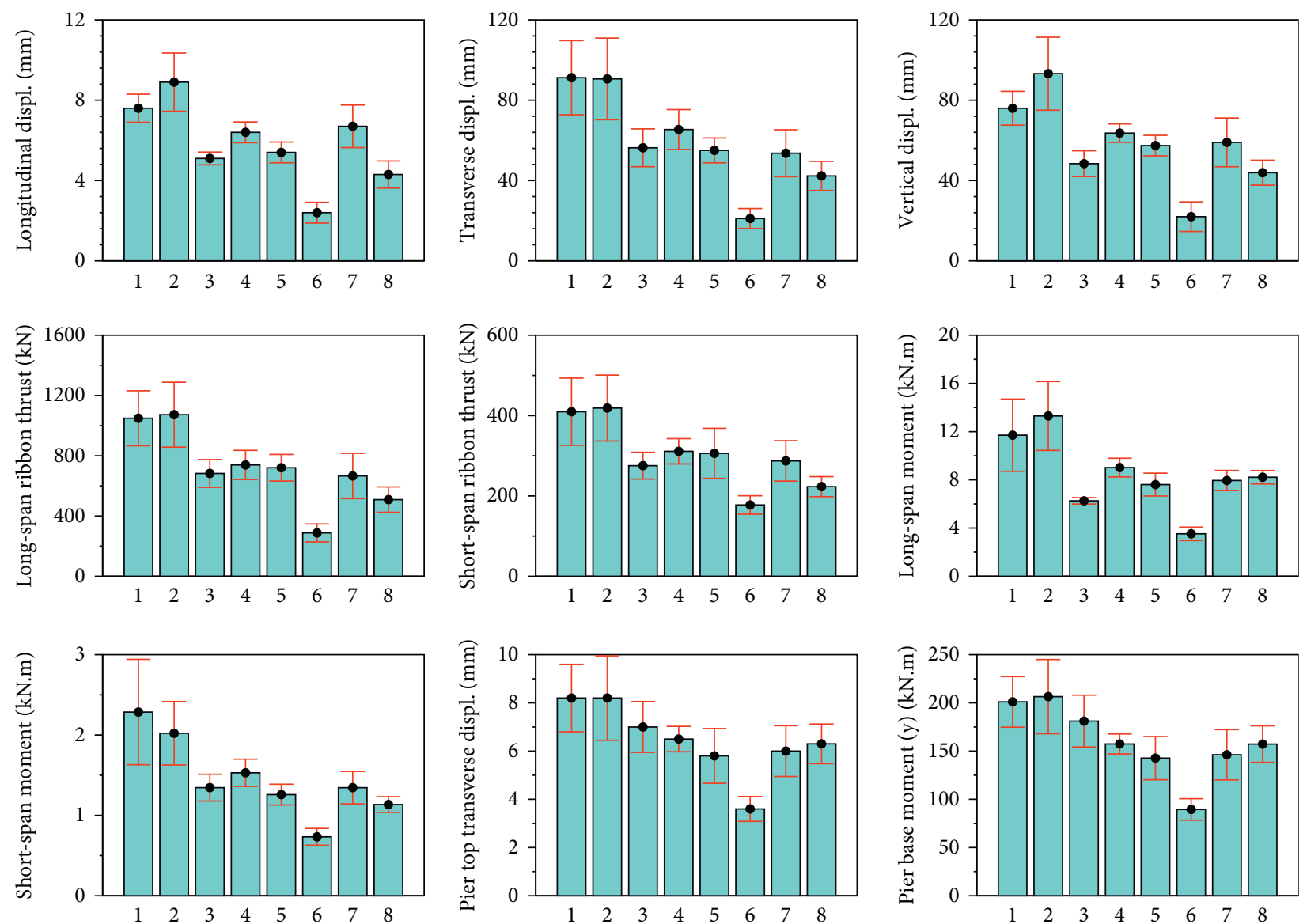

FIGURE 11: Variation of various responses resulting from different orientations.

The negative moment of the ribbon will be limited due to the curved saddle and abutment. Due to the flexibility and the kinetic displacement of the ribbon, the thrust variation is not proportional to the displacement of the ribbon. The response of the pier in the transverse direction is not sensitive to the vertical component because of the orthogonal directions. Third, the vertical component's amplitude is also essential in determining structural responses. Averagely, the PGA ratio between the vertical and horizontal components of the selected records is 0.55 , representing the typical scenario. However, in extreme conditions, the PGA ratio may exceed 1 [26], making the vertical ground motions more significant for estimating the critical direction and the corresponding responses.

For different response indexes, the critical orientations are very different. There is no specific orientation that is critical for all types of response. Thus, for a comprehensive estimation of bridge performance, it is desired to check the responses at all incidence angles. Among the response quantities shown in Figure 9, the negative bending moment of ribbon and the pier displacement and bending moment exhibit significant variation with the ground motion direction. For the bending moment or the ribbon obtained from RSN953, the maximum is about 2.09 times the minimum. The negative bending moment occurs at the top of the pier, where a saddle supports the ribbon. The contact area between the saddle and the ribbon changes during the vibration, inducing a significant variation in the bending moment. For the pier base bending moment obtained from RSN953, the maximum is 2.15 times the minimum, indicating that the pier responses are also sensitive to the variation of the ground motion orientation. Similar results can be observed from the responses of other records.

\subsection{Response Obtained from Pulse-Type Ground Motions.}

The responses obtained from the bidirectional pulse-type ground motions are illustrated in Figure 10. Previous research has shown that the near-fault pulse-type ground motions exhibit significant directionality, as the pulse characteristics are apparent only in limited range of direction. In the analysis, pulse-type ground motions have also been scaled to PGA equal to $0.2 \mathrm{~g}$ to compare between the two types of ground motions. Under such a condition, the aggressive pulse effect may be limited. Moreover, the duration of pulse-type ground motions is shorter than those of non-pulse-type ground motions. It is known that the duration greatly affects the seismic responses of structures; a low-damping structure is expected to generate a stronger vibration under a long-duration excitation [22]. Referring to a similar trend as observed from the results of non-pulsetype ground motions is obtained. 
For directly comparing the responses between the two sets of ground motions, Figure 11 presents the mean and standard deviation of nine response quantities obtained from the ten directions for the eight records. The response includes the tridimensional displacements of the ribbon, the thrust force of the two spans, the negative bending moment of the ribbon, the pier top transverse displacement, and the pier base bending moment. The vertical bar shows the mean responses, and the red line shows the standard deviation interval of the responses over the ten directions. The number on the horizontal axis corresponds to the record number. In the responses, the part induced by the self-weight has been excluded. Generally, non-pulse-type ground motions generate mean responses slightly larger than those of pulse-type ground motions. Notably, the No.6 record with the shortest significant duration causes the smallest responses among the eight ground motions. For the same response, the directional variations of the two types of ground motions are approximately on the same level. The COVs for the nine response quantities are $0.13,0.19,0.16,0.17,0.16,0.15,0.16$, and 0.16 , respectively. The COVs of the responses are still large but smaller than the COVs of the ground vibration intensity measures presented in Figures 3 and 4 . The result suggests that the seismic response of the stress ribbon bridge is sensitive to the ground motion directionality. However, the directionality is insignificantly sensitive to the type of ground motions, and the variation is not as significant as that of the peak values of ground motions. The result obtained from the stress ribbon bridge is consistent with Shahi and Baker [27], who investigated the directionality of the ground motions based on the spectral variation and revealed the insignificance of the type of ground motions (insignificance of the directivity effect).

\section{Conclusions}

This study investigated the variation in response quantities of a two-span asymmetric stress ribbon bridge subjected to bidirectional and tridirectional earthquake ground motions changed with the direction. As-recorded pulse-type and non-pulse-type ground motions were introduced, and the bidirectional pairs were rotated from $0^{\circ}$ to $90^{\circ}$ with $10^{\circ}$ increment. The seismic responses were estimated by conducting a nonlinear time history analysis with the stress stiffening effect in consideration. Various responses, including the deck displacement, ribbon tension force, ribbon bending moment, pier top displacement, and pier base bending moment, were examined based on the numerical analysis. The major findings and conclusions are summarized as follows:

(1) The vertical and the transverse displacements of the ribbon under earthquake excitations are generally greater than the longitudinal displacement. The transverse displacement and bending moment of the pier increase more significantly with the ground motion intensity than other responses, and these responses are sensitive to the ground motion orientation.
(2) The ground motions used for time history analysis has an average acceleration ratio between the vertical and horizontal component of 0.55 . The vertical ground motion may cause an increase in response in a specific direction. However, the vertical component can be ignored in estimating the critical orientation for the responses, including the ribbon thrust force, the ribbon bending moment, pier top displacement, and pier base moment.

(3) The response quantities exhibit different sensitivities to the orientation of ground motion, and there is no single orientation from which all responses are critical. The maximum may be over two times the minimum of the responses over directions, and the coefficients of variation of various responses over directions are from 0.13 to 0.19 . A comprehensive check of the responses in all directions is generally desired for deriving a conservative estimation of the seismic response of the stress ribbon bridge.

(4) The directionality obtained from the pulse-type and non-pulse-type ground motions recorded in nearfault regions is approximately on the same level. The pulse effect can be neglected when estimating the effect of the directionality of the near-fault ground motions on responses of the stress ribbon bridge.

(5) It is noted that the above conclusions were drawn from the analysis based on a typical steel-plate stress ribbon bridge. Other factors such as the structural period and geometries may also affect the directionality effect. It is expected that broader conclusions can be drawn when more factors are comprehensively investigated.

\section{Data Availability}

The data used to support the findings of this study are available from the corresponding author upon request (puwuchuan@whut.edu.cn).

\section{Conflicts of Interest}

The authors declare that there are no conflicts of interest regarding the publication of this paper.

\section{Acknowledgments}

This research was partially supported by the Fundamental Research Funds for the Central Universities (WUT: 2019III109CG). The PEER strong motions database is greatly acknowledged for providing valuable ground motion data. Thanks are due to Mr. Yongqiang Tian for his contribution in part of the data collection work.

\section{References}

[1] A. Goldack, M. Schlaich, and M. Meiselbach, "Stress ribbon bridges: mechanics of the stress ribbon on the saddle," Journal of bridge engineering, vol. 21, no. 5, Article ID 04015089, 2016. 
[2] L. Romera, S. Hernandez, A. Baldomir, and F. Nieto, "Study of pedestrian comfort in a three span stress ribbon footbridge with carbon fibre cables," WIT Transactions on The Built Environment, vol. 196, pp. 139-151, 2020.

[3] Y. Kajikawa, S. Fukada, and H. Yoshikawa, "Vibration characteristics of prestressed concrete stress ribbon," Proceedings of Colloquium on Bridge Vibration, vol. 175, 1997.

[4] Y. Kajikawa, Y. Touge, S. Fukada, and K. Matsumoto, "Vibration test and analysis on 4-span continuous stress-ribbon bridge with a roadway slab," Journal of Structural Engineering, vol. 44 A, p. 835, 1998.

[5] Y. Kajikawa, S. Fukada, and T. Kuribayashi, "Vibration serviceability and characteristics of branching three ways stress ribbon pedestrian," Journal of Structural Engineering, vol. 45A, p. 633, 1999.

[6] Y. Touge, S. Fukada, and Y. Kajikawa, "Vibration characteristics of prestressed concrete stress ribbon bridge with a roadway slab deck due to traffic," Proceedings of colloquium on bridge vibration, vol. 147, 1997.

[7] T. Tanaka, T. Yoshimura, and N. J. Gimsing, "A study on improving the design of hybrid stress-ribbon bridges and their aerodynamic stability," Journal of Wind Engineering and Industrial Aerodynamics, vol. 90, no. 12-15, pp. 1995-2006, 2002.

[8] T. Aso, K. Uno, and Y. Fujimoto, "Dynamic characteristics and earthquake response analysis of three-span continuous stress ribbon bridge," in Proceedings of the 12WCEE: 12th World Conference on Earthquake Engineering, Auckland, New Zealand, February 2000.

[9] I. G. Buckle, Ed., California earthquake of January 17, 1994: Performance of Highway Bridges, National Center for Earthquake Engineering Research. American Society Civil Engineers, Buffalo, NY, USA, 1994.

[10] M. C. G. Soberón and J. M. G. Soberón, "Dynamic properties variation by irregular superstructure and substructure common bridges," Procedia Engineering, vol. 199, pp. 2961-2966, 2017.

[11] K. Kawashima, S. Unjoh, J.-I. Hoshikuma, and K. Kosa, "Damage of bridges due to the 2010 Maule, Chile, earthquake," Journal of Earthquake Engineering, vol. 15, no. 7, pp. 1036-1068, 2011.

[12] R. Akbari and S. Maalek, "A review on the seismic behaviour of irregular bridges," Proceedings of the Institution of Civil Engineers - Structures and Buildings, vol. 171, no. 7, pp. 552-580, 2018.

[13] D. G. Smith, "Field assessment of unforeseen earthquake induced bridge deck movements \& probable effects of geometry," in Proceedings of the 4th European Workshop on the Seismic Behaviour of Irregular and Complex Structures, pp. 26-27, Thessaloniki, Greece, August 2005.

[14] A. S. Elnashai, B. Gencturk, O. S. Kwon, and M A. HashashY, J. KimS, S H. Jeong, and J. Dukes, The Maule (Chile) earthquake of February 27, 2010: Consequence Assessment and Case Studies, , pp. 10-04, Mid-America Earthquake Center, 2010.

[15] M. Torbol and M. Shinozuka, "Effect of the angle of seismic incidence on the fragility curves of bridges," Earthquake Engineering \& Structural Dynamics, vol. 41, no. 14, pp. 2111-2124, 2012.

[16] S. B. Basu and M. Shinozuka, "Effect of ground motion directionality on fragility characteristics of a highway bridge," Advances in Civil Engineering, vol. 2011, Article ID 536171, 12 pages, 2011.

[17] L.-T. Hai, F.-F. Sun, C. Zhao, G.-Q. Li, and Y.-B. Wang, "Experimental cyclic behavior and constitutive modeling of high strength structural steels," Construction and Building Materials, vol. 189, pp. 1264-1285, 2018.

[18] X. W. Huang, J. Zhao, and Z. Zheng, "Parameter calibration and application of GTN model of Q690D high strength steel," Industrial Construction, vol. 48, no. 8, pp. 163-168, 2018.

[19] J. Strasky, Stress-ribbon and Supported cable Pedestrian Bridges, Thomas Telford Ltd., London, 2nd edition, 2011.

[20] Anonymous, Code for Seismic Design of Urban Bridges (CJJ166-2011), China Architecture \& Building Press, Beijing, China, 2011.

[21] PEER, "Pacific earthquake engineering research center: strong motion database," 2013, http://peer.berkeley.edu/smcat.

[22] A. K. Chopra, Dynamics of Structures: Theory and Applications to Earthquake Engineering, Pearson Education, 5th edition, 2017.

[23] S. Hiejima and Y. Fujino, "Approximate solutions for natural frequencies and modes of stress ribbon bridge," Journal of Structural Engineering, vol. 39A, 1993.

[24] J. Radnic, D. Matesan, and D. Buklijas-Kobejevic, "Numerical model for analysis of stress-ribbon bridges," Građevinar, vol. 67, pp. 959-973, 2015.

[25] I. Němec, M. Trcala, I. Ševčík, and H. Štekbauer, "New formula for geometric stiffness matrix calculation," Journal of Applied Mathematics and Physics, vol. 4, pp. 733-748, 2016.

[26] T. Wilson, S. Chen, and H. Mahmoud, "Analytical case study on the seismic performance of a curved and skewed reinforced concrete bridge under vertical ground motion," Engineering Structures, vol. 100, pp. 128-136, 2015.

[27] S. K. Shahi and J. W. Baker, NGA-West2 Models for GroundMotion Directionality, PEER Thesis, Pacific Earthquake Engineering Research Center, University of California, Berkeley, CA, USA, 2013. 